\title{
Slow Traffic Space Planning of Modern Garden City Basing on Analyzing Spatial Characteristics of Land Use--with a Case Study of Xixian New District in Shaanxi
}

\author{
Yuan $\mathrm{Li}^{1, \mathrm{a}^{*}}$, Yanhui $\mathrm{Li}^{1, \mathrm{~b}}$ and Kuanmin Chen ${ }^{1, \mathrm{c}}$ \\ ${ }^{1}$ Changan University, Xi'an City, Shaanxi Province, China \\ 2 Jiangxi Agricultural University, Nanchang City, Jiangxi Province, China \\ am15388648503@126.com, b492827213@qq.com, chenkm@yeah.net
}

Keywords: Slow traffic space; Characteristics of land use; Slow traffic island; Slow traffic center; Slow traffic passageway

\begin{abstract}
Slow traffic refers to a close distance trip mode, giving priority of pedestrian and cycling spatial displacement power. In recent years, people start self-questioning the disadvantages of motorized traffic system and pay more attention to the slow traffic system, due to more and more serious traffic jam, environmental pollution, difficulties of parking, etc. Slow traffic is an important part of urban comprehensive transportation system, which assists and supplements public transport, and it is also a green transportation with sustainable development stratagem (energy, land, economy, and environment). The greenness of slow traffic agrees with the concept of modern garden city, which is also a vital part of the transportation system of modern garden city. It is inseparable between spatial planning of slow traffic and characteristics of urban land use. In order to proceed the planning and designing of slow traffic system, this paper will introduce the related conceptions of slow traffic island, slow traffic center and slow traffic passageway to form the slow traffic's planning scheme in Xixian District, basing on analyzing the characteristics of land use in Xixian District with the conception of garden city.
\end{abstract}

\section{The Connotation of Modern Garden City}

The modern garden city requires urban construction to fully coordinate with land, hill, water and field, etc. It makes fusions of village and city in a large extent, continue historical culture adequately, optimize ecotope, which considers culture as its soul, reckons water as its support, regards road as its skeleton, take greenness as its basement to form the modern garden city [1]

Xixian new district is a national new district, which bear the historical mission of exploring the new-type urbanization. However, it does not mean to excessively pursue economic development index. The inevitable choices are paying more attention to the harmonious development of urban infrastructure construction and environmental development and insist sustainable development.

\section{The Analysis of the Land Use Characteristics in New District}

Groups Development of the Spatial Structure of Land Use. The internal Xixian District exists groups of isolated greenbelt which brought by important traffic infrastructure constructions and ecological cultural sites They are separated by natural water system, cultural relic ruins, rail facility and freeway infrastructure [2]The land use in Xixian District appears fractured groups and the land was connected by a lot of continuous zonal lands for non-construction. From the view of the spatial distribution of land plate, the distance of two nearby land plates is less than 200 meters. What's more, the areas of land plates are usually between 5 to 25 square kilometers. The spatial size of the interior of land plates is very sui Table for develop slow traffic. The new district is divided into land plates by infrastructure constructions and scenery sites zones. It can be regarded as an independent slow traffic space relatively, and then bring into the conception of slow traffic island, slow traffic center and slow traffic zone. 
Small Construction Land, Good Land Ecological Base. The farmlands, orchards, water area, green buffers have occupied 51.02\% of the total planning area of used land, and the non-construction has reached $69 \%$, which is very suitable to establish a high-quality slow traffic environment It reflects that Xixian New District pay attention to ecotope during construction with groups' arrangement and crossed forests and fields of spatial arrangement. It can not only keep a good ecological pattern, but also can place Xixian New District in a green countryside, which creates a statuesque ecological garden with a harmonious coexistence of human and environment.

Large Cultural Relics Protective Land Area, Numerous Tourist Attractions in District. The new district has numerous tourists' attractions with profound historical sediment. It continues three culture belts with urban imperial mausoleum culture, culture of Qin and Han, ancient capital culture. It explores and renovates environments to form demonstrated garden, centralizes museum and cultural creative tourism industry, and corresponds with Weihe River ecology landscape belt. It considers Changan City as a link to connect Weibei imperial mausoleum relics and Zhou\&Qin\&Han ancient capital relics, builds national Qin-Han cultural exhibition area and international metropolis ecological cultural relics park. [3]

Many Green Belts Which Facilitating the Connections and Links of Internal Slow Traffic Space. There are Weihe River, Jing River, Feng River in the district, which belong to Yellow River System. Weihe River is the first order affluent of Yellow River, which across the whole territory from west to east, up to $50 \mathrm{~km}$. Weihe River flows from south to north, and Jing River flows from north to south, reaching into Weihe River. In addition, there are some small tributary systems, such as Shahe River and Zaohe River.

\section{Building Slow Traffic Space Which Matches the Land Use Characteristics of the New District}

Integrating the touristic and leisured city features of Xixian New District, it will build a slow traffic environment which is suitable for human, establish a slow traffic space which obey "people-oriented" idea, lead "slow going-out and public transportation" trip mode, support the construction of garden city. Finally, it will complete a safe, convenient, high-efficient, low-costing slow traffic system, which adapts to urban development, coordinates with motorized vehicle development, join together well with public transportation. [4] The slow traffic space mainly includes slow traffic island, slow traffic center and slow traffic passageway.

The Planning of Slow Traffic Island. Slow traffic island restrains going out of transiting, result in difficulties of slow traffic, because it is cut by wide major road such as railway, highway, express-way and water system massif and large sites. [5] Considering it is separated by express-way and highway facilities in the internal land plate, it will divide land plates into a number of slow traffic island. Slow traffic island is the fundamental element to build slow traffic priority access network.

The characteristics of slow trip mode in the internal slow traffic islands led by different characteristics of land use are different. The planning will divided slow traffic islands into three parts. One is commercial slow traffic island, whose core is commercial blocks. Pedestrian traffic in the part is active throughout the whole day. It has a large amount of going-outs, several peak traffic hours. It's entertaining and commercial activities are pretty frequent and its public transportation is advanced. The second one is large-scale residential slow traffic island. In this part, there is no obvious peak traffic hour, and its outside communications are frequent. The internal urban public transportation service level is high while in the city fringe it is relatively weak. The last one is job-housing balanced slow traffic island. It has obvious morning and evening peak traffic hours, and the public transportation is undeveloped, which has a low traffic balance.

This planning combines five districts' latest layout scheme of land use to plan and design 3 kinds of slow traffic islands, at a total of 48 slow traffic islands. 


\section{Slow Traffic Center}

Slow traffic center refer to the "core" area, which mainly includes public transport stations, large-scale public facilities, main functional partial-areas. The public transport stations include orbit station, tramcar stations, and junction stations, regular bus original and terminal stations. The public facilities include school, hospital, gymnasium, park cultural entertaining facilities and so on. The main functional partial-areas contain large-scale living quarters, commercial center, larger industrial partial-area.

Slow traffic center is the main attractions of urban slow traffic. Usually its radiant scope is among 1-2 km. Pedestrian and cycling going out has its own specialties, and cannot be displaced by motor vehicle. So it accords with "people-oriented" conception, low-carbon green idea and sustainable transportation development and presents slow traffic center layout scheme, builds pedestrian and cyclist prioritized passageway among the radiation scope. [6]

From the definition of slow traffic center, the slow traffic center in Xixian New District can be divided into three types: public transport station, large public facilities and main functional partial-areas. Specific division follows Table 1.

Table 1 The Layout Scheme of Slow Traffic Center in Xixian New District

\begin{tabular}{|l|l|l|}
\hline \multicolumn{1}{|c|}{ Type } & \multicolumn{1}{|c|}{ Content } & \multicolumn{1}{c|}{ Radiation Radius } \\
\hline $\begin{array}{l}\text { Public } \\
\text { Transport }\end{array}$ & $\begin{array}{l}\text { Includes orbit stations, } \\
\text { tramcar stations, junction } \\
\text { stations, regular bus original } \\
\text { and terminal stations }\end{array}$ & $\begin{array}{l}\text { It } 2 \mathrm{~km} \text { in the fringe of } \\
\text { rail transit, tramcar stations, } \\
\text { new city junction stations. } \\
\text { It is } 1 \mathrm{~km} \text { in the center. }\end{array}$ \\
\hline $\begin{array}{l}\text { large public } \\
\text { facilities }\end{array}$ & $\begin{array}{l}\text { The layout of all kinds of } \\
\text { facilities, according to the } \\
\text { new regulatory scheme in } \\
\text { various new cities [4] }\end{array}$ & $\begin{array}{l}\text { it 2km among the } \\
\text { regional public facilities, } \\
1 \mathrm{~km} \text { in downtown public } \\
\text { facilities, 0.5km in groups } \\
\text { public facilities. }\end{array}$ \\
\hline $\begin{array}{l}\text { main } \\
\text { functional } \\
\text { partial-areas }\end{array}$ & $\begin{array}{l}\text { Includes large-scale living } \\
\text { quarters,commercial blocks, } \\
\text { industrial partial-areas. }\end{array}$ & $\begin{array}{l}\text { Intensive short-distanced } \\
\text { going } \\
\text { motorized traffic at some } \\
\text { extent. }\end{array}$ \\
\hline
\end{tabular}

\section{Slow Traffic Passageway}

The Slow traffic passageway includes pedestrian passageway and cycling passageway, which would be contained in this planning. It can be divided into leisured functional passageway and commuter functional passageway due to different functions. Leisured functional passageway can be brought into green passageway. Commuter functional passageway can be divided into corridors, collector-distributor roads and connecting passage according to its different connections with transportation. [7] Slow traffic corridors are the main steams of slow traffic, which is responsible for the middle and long -distanced going out. So the plan decides that slow traffic corridors will undertake the mission of long-distanced crossing city's going out in Xixian District. Slow collector-distributor roads supplement the slow traffic corridors, which is responsible for the short and middle distanced going out. Therefore, the layout scheme will verify that slow traffic corridors assume the crossing transportation connections among different new cities in Xixian District. And the slow traffic corridor is mainly distributed in slow traffic islands and slow traffic centers. [8]Slow traffic connecting passageways are responsible for the connecting functions of transit stations, junction stations and large traffic facilities.Therefore, the layout scheme will verify that connecting 
passages assume the internal transported connections among several of groups of new cities in Xixian District, which is arranged around the slow traffic center. These three slow traffic passageways are expressed as Fig. 1, Fig. 2 and Fig. 3.

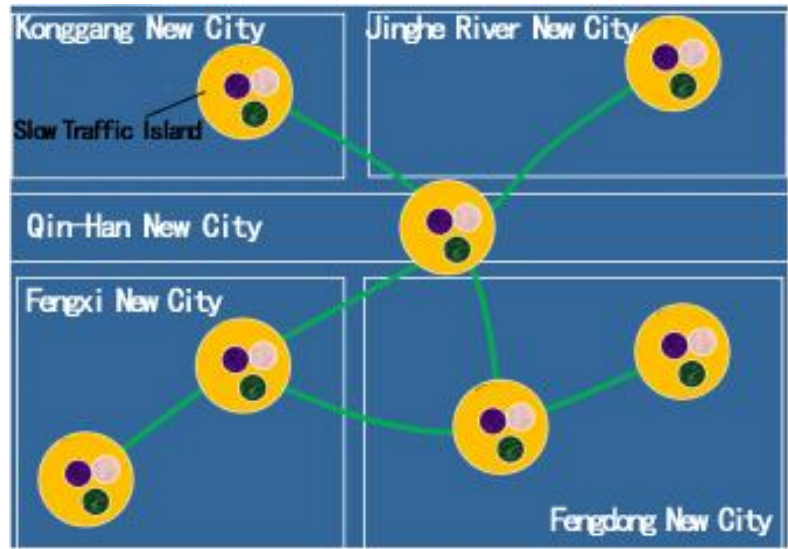

Figure 1. The Layout of the Slow Traffic Corridors

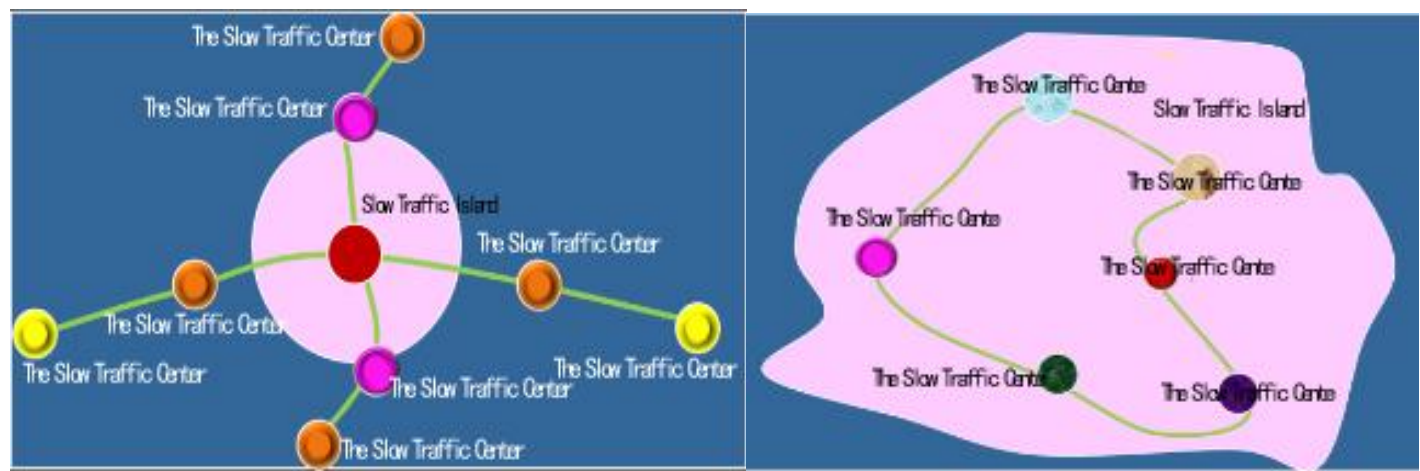

Figure 2. The Layout Diagram of the Slow Traffic Collector-distributor roads

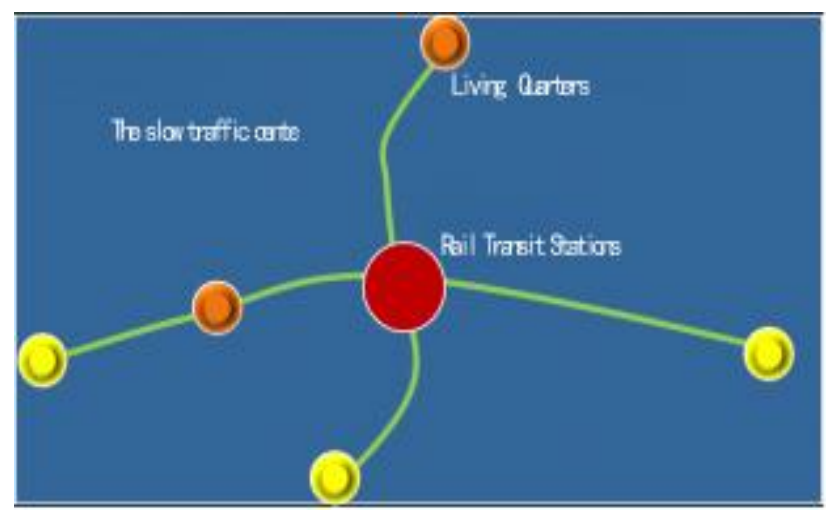

Figure 3. The Layout of the Slow Traffic Connecting passage

To sum up, different kinds of slow traffic passageway bares different transportation requirements. It formulates different layout principles according to the different functions of slow traffic corridors, collected-distributed roads and connecting passageways in Xixian District. More details are shown as below: 
Table 2 the list of Slow Traffic Passageways Layout Principles

\begin{tabular}{|c|c|l|}
\hline NO. & $\begin{array}{c}\text { Slow Traffic } \\
\text { Passageway }\end{array}$ & Layout Principle \\
\hline 1 & Corridor & $\begin{array}{l}\text { Connecting slow traffic island, bare the } \\
\text { middle and long-distanced crossing } \\
\text { cities going out in new district }\end{array}$ \\
\hline 2 & $\begin{array}{l}\text { Collected-Distr } \\
\text { ibuted Roads }\end{array}$ & $\begin{array}{l}\text { Connecting slow traffic center, bare the } \\
\text { internal middle and long-distanced } \\
\text { going out in new district }\end{array}$ \\
\hline 3 & $\begin{array}{l}\text { Connecting } \\
\text { Passageway }\end{array}$ & $\begin{array}{l}\text { Surrounding the slow traffic center, bare } \\
\text { the internal short- distanced going out in } \\
\text { new district. }\end{array}$ \\
\hline
\end{tabular}

\section{Conclusion}

The paper considers slow traffic space as its discussion object. Through expressing the connotation of modern garden city, it gets the importance of the existence and development of slow traffic system. On the base of analyzing the characteristics of land use in Xixian District, Shanxi Province, it introduces the conceptions of slow traffic island, slow traffic center and slow traffic passageway. Finally, it forms layout scheme of slow traffic island and slow traffic center, the classification layout scheme of slow traffic passageway, the layout of pedestrian and bicycle priority network. All in all, this paper intends to make a good contribution to the economic development and ecological improvement of the new city through plan and complete this city's slow traffic system.

\section{References}

[1] Miaolei Xia, (Tianjin 2014-09-23), The $9^{\text {th }}$ Urban Development and Planning Meeting Vol2014, P125,

[2] Urban and Rural Design Planning and Research Institute in Shanxi Pro.(2010-2020)The Comprehensive Planning of Xixian New District,

[3] Urban Planning and Designing Institute in Xian (2010-2020), The Partition Planning of Xixian New District

[4] Yune Gao (Master in Changan Uni, 2013 China)The Space Design of Urban Slow Traffic System P28

[5] Q. Yang: Spatial Planning and Improved Traffic Design for Historic

[6] District (MS., Xi`an University of Architecture and Technology, China 2014),p.59

[7] Xi'an city planning design and research institute: Xi'an urban general planning, (2008-2020)

[8] X.J. Niu: Study on The Slow Traffic System in Ming City Area of Xi'an (MS., Chang'an University, China 2015), p.38 